\title{
(Re)Tracing the Everyday 'Sitings': A Conceptual Review of Internet Research 15 Years Later
}

\author{
Shannon Elyse Prince \\ Michigan State University
}

\begin{abstract}
In 2003, Kevin Leander and Kelly McKim sought to move the separate ethnographic work in physical spaces and work in online spaces toward a connective ethnography. Rather than broadly update the seven themes they originally proposed, I re-group and re-examine the seven themes by using evidence published since 2003. The themes of the meshed on/off-line realm, made visible through the work of connective ethnography, illustrate the separation, influence and flow of one realm more clearly and convincingly than the evidence available in 2003. I conclude by describing the encumbrances to the meshing of the on/ off-line realm.
\end{abstract}

Keywords: connective ethnography; internet research; online offline spaces; new literacies

\section{Introduction}

In 2003, Kevin Leander and Kelly McKim made the argument for connecting scholarship on physical spaces with that of online spaces. They named this fusion of scholarly areas connective ethnography, termed by Christine Hine (2000, as cited in Leander \& McKim, 2003). At that time, they asked: "How might we develop research practices and frameworks that allow and even propel us as researchers to travel with adolescents as they create and dwell in online and offline sites?" (p. 212). Before answering this question, they critiqued a misconception assumed in much of the scholarly literature that online and offline realms were separate. They argued that the online and offline were one realm. Their argument illustrated seven themes (pp. 218-223) "found to be particularly important for reconceiving Internet research as connective ethnography" (p. 218). These themes emerged from a small body of work that examined the on/off-line realm in 2003. Given the 15 years since Leander and McKim's argument, has research using connective ethnography supported, extended, or countered their seven themes about connective ethnography?

\section{Approach}

The method for gaining these insights began with a systematic search of the literature by working chronologically from the time of Leander and McKim's publication in 2003. 
Their original work had been cited 367 times. Focusing on empirical studies from peer reviewed publications resulted in 102 published studies. The pool was narrowed to 49 by including only studies using connective ethnography as a methodology and specifically citing Leander and McKim's work.

\section{Themes}

Leander and McKim (2003) argued against "static" (p. 217) conceptions of space. The Internet, they reasoned, was not "absolute, akin to a container filled with objects" (p. 217). Rather, it was "dynamic", "ongoing", and a space of "co-construction" (p. 217). Thus, the seven themes proposed in their original work illustrated and argued for a dynamic oneness of the on/off-line realm. Metaphorically, this dynamic oneness was a rmeshing, of the so-called on-line and offline realms, made possible and visible through the lens of connective ethnography.

While a connective ethnographic view of the on/off-line realm imagines the separating of online and offline as counterproductive, there are instances where making distinctions between an online practice and an offline practice are useful. For example, in a visible way, the reading of a hardback textbook at a coffee shop is an offline practice, while reading a blog on a laptop in that same coffee shop is online practice. But how can one account for the invisible meshing in which each of these literacy practices is embedded? In both cases, the borders of online and offline realms are 'blended' (Leander \& McKim, p. 229) because of the influence and flow of practices and ideas across the border 'lines' of these realms as they mesh.

The themes proposed by Leander and McKim in 2003 illustrate such a meshing. Rather than broadly update the literature supporting the seven themes they originally proposed, the seven themes are re-examined and re-grouped. The themes, made visible through the work of connective ethnography, illustrate the separation, influence and flow of the online and offline realms.

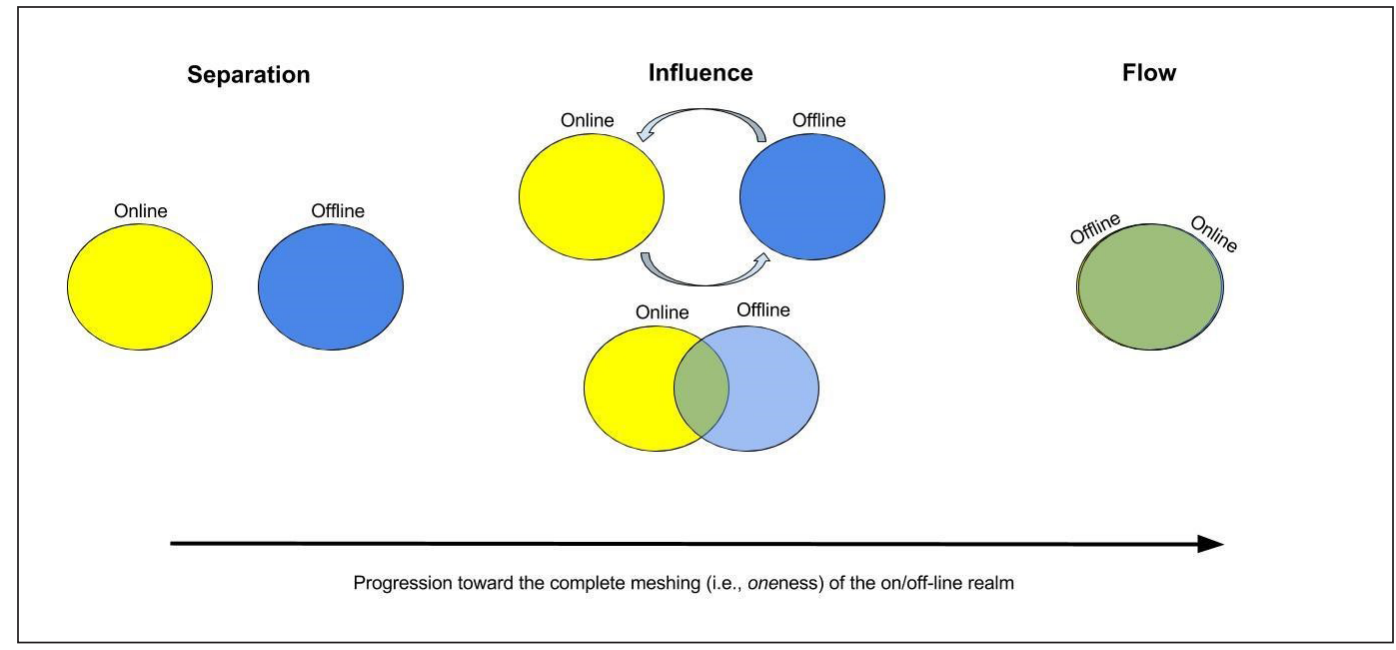

Figure 1. Conceptual progression of the on/off-line realm 
Through connective ethnography, the forces of influence and flow form a progression which moves from the complete separation of off-line and on-line realms toward a complete meshing (i.e., oneness) of the on/off-line realm. The starting place for this progression is the complete separation of the online and offline realms. Leander and McKim's work argued that this separation was counterproductive. Here, the online and offline realms are viewed as separate and do not influence each other.

The first phase of this progression toward the complete oneness of the on/offline realm is influence. The first three themes below illustrate the influence that one realm has on another. This influence goes back and forth but influence makes distinctions between the realms. While influence has moved beyond the complete separation of online and offline realms that came before, themes that illustrate influence do not suggest they are one realm.

The next phase in this progression toward the complete oneness of the on/offline realm is flow. The latter four themes below illustrate the flow resulting from the meshing of realms and describe how people "travel among and connect diverse situations as literacy practices" (Leander \& McKim, p. 230). Flow suggests that there is a continuous back and forth movement between realms, making the boundaries between one realm and another progressively indistinguishable.

The next phase in this progression, to be explored by future research using connective ethnography, moves literacy and social practices to occur within one realm at all times (i.e., a complete oneness of the on/off-line realm). These future steps will move beyond making any distinctions between realms.

\section{Influence}

\section{"Participants make meaning of their experiences across online and offline spaces" (p. 218)}

At the time Leander and McKim published their piece, few empirical pieces existed exploring how participants make meaning of their experiences across the on/off-line realm. They suggested that researchers could explore not just how identity work is done online but the "mundane" (p. 219) identity work done in the on/off-line realm. In several studies exploring children's' interacting on computers in a shared space, such as a computer lab, findings suggest that the children made meaning of their play online through a seamless movement of interaction in both the online and offline spaces. Kafai (2008) studied the gender-specific practices of children as they played on the popular children's social networking site (SNS), Whyville. Kafai found that the distinction between what was termed playing on Whyville and what was playing in-person was no longer distinct. This synthesis not only suggested that the online and offline practices were interrelated, but the children used the online space to directly influence and interact in the offline space. 
This idea that meaning making depended on a seamless synthesis of both the online and offline contexts was further explored by similar studies of the Whyville SNS. Searle and Kafai (2012) explored practices of boys in Whyville. Boys gained currency through scams, a distinctly transgressive practice not intended by the site's programmers. Other boys used the avatar design system within the site to play with multiple identities. Similarly, Fields and Kafai (2010) explored how in-game projectile throwing spread across an offline grouping of children. Wohlwend, Vander Zanden, Husbye, and Kuby (2011) used Webkinz, a SNS like Whyville, to examine the interactions involving the "physical actions with here-and-now objects" (p. 145), in this case the computer, that are mediated or "meaningfully altered" (p. 145) by the online environment. Interestingly, as children ignored the on-screen print directions, they collaborated and solved problems to mediate their own experience through the game.

Other studies explored this theme of meaning making across online and offline spaces through an ethnographic exploration of youth's online and offline practices. Leander and Mills (2007) illustrated the concept of digital flow by examining how one adolescent worked with friends from school and peers online to design an online role-playing game. The project required adapting the flow of skills and resources across varying landscapes, both online and offline. Similarly, others have explored how interactions across different locations were made meaningful across online and offline spaces (Davies, 2013; de Almeida, Delicado, de Almeida Alves, \& Carvalhom, 2015; Leander \& Lovvorn, 2006).

Finally, an analysis of children's Internet searches and the websites they frequently visited found that the searches were most influenced by their offline interests such as sports. Even though most of their purchasing was done offline, the children frequently checked online stores to compare prices and see what was new in their favorite stores. Though it may not be surprising that online searching is mediated by offline interests for these children, the online act of searching for websites was made meaningful through offline environments.

\section{"Internet-based social practices shape offline practices of identification" (p. 219)}

Leander and McKim suggested that offline identity categories, such as adolescence, become "stitched together with particular Internet practices" (p. 219). A study by Wohlwend (2009) observing children playing in kindergarten and first grade classrooms provides a pointed illustration of this theme as children used physical toys to mimic digital devices. The Internet and technology have become such an integral and visible part of the children's lives that their offline play, even when devoid of actual internetenabled technology, is influenced by technology-based social practices.

Several studies have explored the use of social networks, such as Facebook, in the identity development of adolescents and young adults. Students' offline identities are increasingly being influenced by social practices on SNS (Madge, Meek, Wellens, \& Hooley, 2009; Stirling, 2014). The social practices and norms of online affinity groups have also been shown to influence offline identity practices. Stewart (2011) explored how 
women interacted with online church groups and how these interactions contrasted or supported their offline church-going practices. Similarly, Jonsson and Muhonen (2014) examined how two young people expanded their limited, local, offline access to manga and other manga enthusiasts at the local library through access to online affinity spaces.

Considering adolescents particularly, Bulfin and North (2007) found that students used their identities around their use of technology to engage in covert acts of rebellion in the technology-resistant space of school, actively using their Internet social practices, playing games, chatting, and listening to music, to influence their offline identity. In a similar study, Aarsand (2008) found adolescents using covert ways to access MSN Messenger, an application the school forbids students to use.

\section{"Offline places are embedded within and reproduced in cyberspace" (p. 220)}

Leander and McKim noted: "It is perhaps too much of a truism to note that in creating anything 'new' we are always bricoleurs, using scraps of old materials, familiar structures, and well-worn stories" (p. 220). They pointed out the "geographic metaphors" (p. 230) used in for the Internet: "chat rooms, home pages, online communities, virtual landscapes and worlds," (p. 230, emphasis from original). Lewis and Fabos (2005) found that when participants used IM with peers, they utilized visual elements to further illustrate their message. To examine social interactions in a visual and textual online environment, Williams (2007) performed participant observations in Cyberworld, finding that the presence of lurkers in online forums, discussion boards, and chat rooms were essentially invisible to observers, while others interacted with a 'physical' avatar reproducing the physical body one uses when entering offline places.

Social practices used offline are represented in online spaces in Kafai, Feldon, Fields, Giang, and Quintero's (2007) research of the children's SNS Whyville, discussed in previous sections. Programmers of Whyville launched a virtual epidemic called Whypox. Their research found that the epidemic mimicked the feelings of shame and isolation, mirroring how one would feel if they had a physical affliction.

Others have examined how physical geographic locations are embedded and represented in offline spaces. Walker (2010) analyzed the discussion forums in Philadelphia, Pennsylvania. Described as a "digital layer atop their own physical space" (p. 35), participants reported local news witnessed around the city, shared information on construction projects, restaurant closings and openings, and road closures. Arora (2011) made a similar argument in her conceptualization of online "leisure spaces as virtual parks" (p. 114).

Finally, affinity spaces, where people share specialized, common interests, are reproduced and embedded online. Members within the affinity space define their belonging through what Lammers (2013) called "regulative discourse" (p. 376). This regulative discourse defined the rules of appropriate behavior and conduct within the shared space. Lammers examined the fan fiction writing group based around the game the Sims 3, finding that 
despite the young age of users and the assumed informal nature of an online forum, regulative discourses dominated the interactions within the group.

\section{Flow}

\section{"Experiences in cyberspace are often not seen as exceptional by participants" (p. 218)}

Leander and McKim (2003) found that those participants frequenting online environments did not find them to be separate from their 'real' life. Continued research has found that online experiences are considered unremarkable when used at home or in school. Mallan, Singh, and Giardina's (2010) work contributed to this theme by mistakenly assuming youth saw their technology use as elite or exceptional when they did not. Similarly, Humphreys, von Pape, and Karnowski (2013) sought to understand students' mobile internet use, that is using the Internet on a mobile device such as a cell phone. They found that for these participants, there was no need to distinguish between mobile Internet use and non-mobile Internet use. Lewis and Fabos (2005) interviewed young people about their online practices using an instant messaging (IM) program, AOL IM and found that the technology, as such an integral part of the participants' social life, made the usage of IM normalized to the point where one participant stated, "everybody does it” (p. 470).

This commonplace-ness of the Internet was also seen in Perez-Fragoso's (2011) case study of Martha, whose social life fluidly moved between online and offline spaces. For Martha, her interest in graphic design and her social nature flowed through her on/ off-line activities. As the Internet and technology continued to be commonplace and fluidly integrated into the everyday lives of people, researchers such as Stæhr (2015), exploring interactions on SNS, found that everyday language used by participants on Facebook corresponded to their offline language use. Recently, Kofoed and Larson (2016) investigated how youth aged 12-17 practiced and maintained relationships on Snapchat. Though the participants used Snapchat with seemingly great pleasure, they saw the exchanges on the app as unremarkable or even irrelevant.

As we continue to move along the progression of on/off-line as separate, to being influenced, to flowing, and beyond, this theme may be the first to not need further exploration. The recent research suggests that participants do not find any significance in online experiences compared to offline experienced. It was the researchers themselves (e.g., Mallan, Singh \& Giardina, 2010; Humphreys, von Pape \& Karnowski, 2013) that fell victim to assuming online experiences were exceptional, not the participants.

\section{"Online technologies extend rather than replace offline relationships" (p. 219)}

In support of the theme that online technologies extend rather than replace offline relationships, studies since Leander and McKim's piece have supported the notion that 
the Internet nurtures social relationships. Using online technologies to communicate with peers, such as chat rooms, SNS, and texting, serves as an extension of the social interactions that occur during the normal day. These interactions have become a normal part of a shared 'life rhythm' (Davies, 2013, p. 154). Warner (2016) found that, in a study of smartphone ownership among low- and high-income teens, not all of these technologies were created equal in their extension of offline relationships. Participants noted it was appropriate to direct message, away from a public forum such as a Facebook feed, or to talk on the phone. Certain interactions were therefore more suited for public forums.

Those studying Facebook users at university have also found that the social network extends the offline social world of attending university. Madge et al.'s (2009) participants used Facebook to keep in touch with friends they made prior to university and share their university experiences. Facebook was also used to plan social events, join Facebook groups tied to offline university groups, and keep in touch with peers also attending the university. Stirling (2016) found that students using Facebook as a backchannel during lectures were able to discuss areas of struggle either synchronously during the lecture or asynchronously around the time the class met. This backchannel led to students becoming friends offline, and nurture these friendships through continuous interactions, when students otherwise may never have communicated. In this way, Facebook is extending both current and previous offline relationships. Facebook, then, serves as a 'window' through which offline users can look at everyday experiences of friends (Davies, 2012, p. 27).

While some might assume that the Internet is separating or isolating people, the research points to online technologies serving as extensions into offline social networks. Most frequently, studies have taken up and supported this theme through the examination of adolescent social practices in online spaces. Online spaces, therefore, nurture offline relationships, and this nurturing is not particularly difficult or exceptional.

\section{"National identities are practiced in cyberspace" (p. 221)}

Despite the proliferation of globalization, the Internet has continued to 'give people back their sense of themselves as special and particular' (Miller \& Slater, 2000 , p. 115 , as cited in Leander \& McKim, 2003). One sense given back is a national identity, which are practiced and expressed online. McGinnis, Goodstein-Stolzenberg, and Saliani (2008) examined the digitally mediated, national-identity expression of three high school students, a Bengali-American male, a Colombian female, and a Jewish-American female. Not only were their expressions on MySpace and personal blogs direct reflections of their offline worlds, but the participants expressed their national identity through "multiple modalities, media, and language forms" (p. 301). Lam's (2006) case study of immigrant Chinese high school students revealed that degradation within the Chinese student population at school led participants to seek out avenues of expression online. These students were able to continue to learn and speak English with peers, but the chat rooms repositioned them beyond English-language learners in an English- 
speaking country. Rather, they could express their experiences in a "Chinese diaspora network» (p. 186) and interest in anime youth culture.

A more recent approach to this theme appears in the work of Prinsen, de Haan, and Leander (2015) examining four types of social networks taken up by 24 participants. These networks include: (1) Fragmented networks, (2) large, ethnically homogeneous networks, (3) dense family-centered networks, and (4) small, mainly offline networks. These networks represent the nuanced and emerging ways in which national identities are practices within social networks. National identities are being expressed multimodally and with nuanced language forms that allow people to find camaraderie and build identity in the on/off-line realm.

\section{"Online and offline spaces are dynamically co-constructed and interpolated" (p. 222)}

The final theme identified by Leander and McKim was only supported, at the time, by the distinct work of Nina Wakeford (1999, as cited in Leander and McKim, 2003) and her ethnography of the first cybercafé in London. Since then, the theme that online and offline spaces are co-constructed and interpolated has been further supported by many researchers. Several case studies have examined how physical geographic locations are interwoven with a corresponding online space. For example, Dochartaigh (2007) analyzed the territorial conflict between the two neighboring districts Whitewell and Whitecity in Belfast, Ireland. As supporters of either side posted to three specific websites associated with the districts, Dochartaigh observed a direct impact on the patterns of street violence. In this case, technology "facilitates the extension of territoriality as a strategy for exercising power" (p. 489). This point is significant, as it further illustrates that the online space (the websites) and the offline spaces (the neighboring districts) were dynamically co-constructed and interpolated. In another case study, Merchant (2007) observed a community street piano and its corresponding website (advertised on the physical piano). The street piano became a local news story when a public attempt was made to have the piano removed by local authorities, leading to increased popularity in the piano and the website. Finally, Wargo (2015) observed the case of one youth's composing on Snapchat as he navigated a "spatial story" (p. 48). Wargo suggested that such storytelling through Snapchat "blur[s] bifurcations between real/virtual and of the past/present" (p. 55). In this way, it is clear that the co-constructed and interpolated nature of the online and offline has continued to progress since Wakeford's work.

This theme has been explored in educational settings, resulting in implications for educators and educational researchers. This theme in and of itself has natural implications for the classroom, a traditionally offline space, that has not only been further constructed and interpolated with technology but has become entirely mediated by technology. Lund (2006) surveyed Norwegian teachers as they participated in an online course, looking particularly at their language use on the online classroom website. Findings suggested that the online classroom adds the 
contextual dimensions of where and when, as participants engaged with the classroom in different locations across different times and with varying modes. This resulted in a digital classroom space that exhibited, through their use of Englishes, the in-school and out-of-school contexts of participants. In another study of digital learning environments co-constructed with offline spaces, Mallan, Foth, Greenaway, and Young (2010) observed a learning experience of middle schoolers in Second Life. Participants were not only seen to be fully emerged in the workshop, but the experiences facilitated "the development of informed exchanges of ideas, stories, and viewpoints" (p. 216). The online experience was made authentic through a clear link to an offline space, where the offline space could be virtually constructed.

Burnett (2014) found that an offline classroom environment is always "under construction" (p. 194), particularly when technology is introduced. Described as "interactions around screens" (p. 199), Burnett observed students as they worked on laptops for the first time in class. While some students positioned themselves as experts and came to the aid of peers, others individualized their work by blocking their screen with barriers. Burnett, however, argues that this case exemplifies the "'classroom-ness' of digital literacy practices" (p. 194). Classroom spaces, like digital spaces, are hybrid and fluid spaces continuously under construction. It remains unclear if these classroom spaces are as able to be co-constructed as other spaces students meet.

\section{Encumbrances}

By re-examining and re-grouping Leander and McKim's original themes using empirical research drawing specifically from that work, two new themes emerged. Both, however, disrupt the notion of influence and flow. More recent empirical research illustrates apparent encumbrances to the influence and flow of the on/offline realms, particularly in educational settings (see Figure 2).

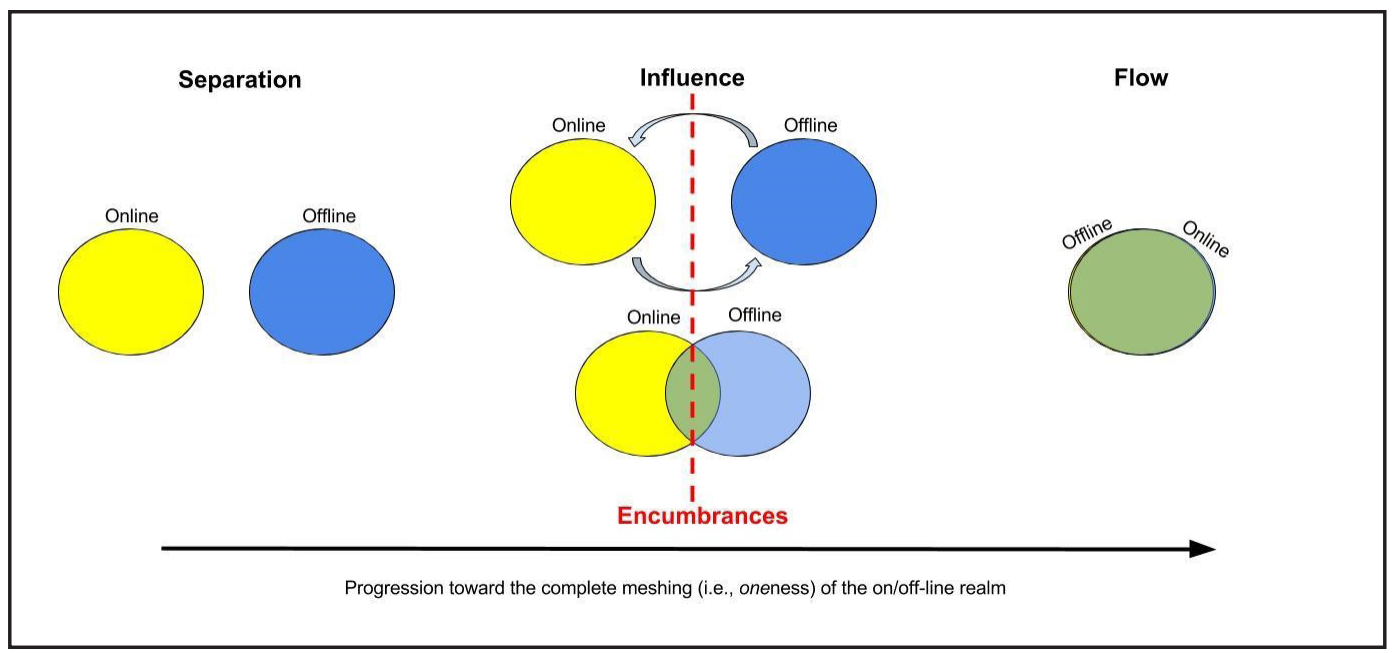

Figure 2. The impact of encumbrances on the progression of the on/off-line realm 
The themes illustrating encumbrances act as disruptors and impediments to the forces of influence and flow, which are the forces that progresses us toward a oneness of the on/offline realm. These encumbrances must be addressed and rectified as we seek to continue to move forward on the progression.

\section{Disconnections disrupt the influence and flow of literacy practices across school and online settings}

One, perhaps troubling, theme that continues to emerge from the research is that the literacy practices endorsed and enforced in school settings do not align with online settings. Through a case study, ethnographic exploration of one participant, Clare's, text production online and text production in school, Dowdall (2006) discovered a "sort of dissonance" (p. 153) between the identity Clare had when composing online and the identity when composing for school, describing these identities as "crash[ing] with an absolute lack of harmony" (p. 153). Through Wohlwend et al.'s (2011) study of children's use of Webkinz in a classroom computer lab setting, this disconnect played out in a different way. Here, the classroom computer space, particularly speech and sound, was controlled by an adult authority, requiring participants to play quietly without any sounds emitting from their computers. Social practices such as working quietly on the computer, responding quickly to the teachers' requests, and working alone were social practices very different than how the same participants might interact with the SNS and the computer without such authoritative expectations of behavior. One can perhaps conclude that even when students can interact online in school, the experience still lacks harmony with online interactions at home. It is important to note, however, that it is only through the complete picture of on/offline practices that connective ethnography affords can researchers identify the disconnect between school and home and begin to resolve these disconnections.

\section{There is resistance to SNS and school settings}

Potential implications and applications for educators to incorporate these themes into their teaching practice have been suggested through the research work drawing from Leander and McKim. First, however, it is important to note that studies have found a of resistance or adversity young participants feel toward the inclusion of SNS, such as Facebook or Snapchat, in classroom settings. For example, Madge et al. (2009) found participants surveyed were not interested in using Facebook in formal teaching situations. Kofoed and Larsen (2016) experienced this resistance through his participants use of "antianswers" (p. 8) to survey questions about how users interacted with Snapchat. These antianswers included responses such as "none of your business" or "it's private" (p. 8). This sort of response was so common, Kofoed and Larsen included it as an analytical category during data analysis. There can potentially be several reasons for this resistance, a topic worth taking up in future research. One reason could be that students have not experienced authentic, worthwhile, or rewarding experiences using SNS in the classrooms. This reason is perhaps supported by the previous section, where a clear disconnection between classroom uses and expectations of technology use and those uses at home is shown. 
Despite this resistance, research exploring potentially promising integrations of technology and hybrid flows of on/off-line spaces in the classroom are worth noting. Vasudevan's (2010) studied the case of two youths using various digital tools to produce multimedia narratives. The use of portable digital devices, such as the PlayStation Portable and cell phones, was particularly significant, as such allowed for the composition to occur across multiple contexts. This naturally led to "intentionally blurring artificial in/out of school binaries that are institutionally reinforced" (p. 78). In a similar case study, Schmier (2014) observed participants in a classroom where students had access to digital tools. Furthermore, the students were expected and encouraged to design their own topic explored and the product to be created. Such an environment resulted in one participant, normally considered underperforming in her classes, to become an author and designer of a project of significance. Another participant harnessed the expertise of his peers in the class to provide feedback on his project, thus increasing the participants' confidence as a writer in both this class and his other core classes. Barden (2013) used the Facebook group tool to provide a space for students to explore a topic decided collaboratively. The students, deciding to research and write about the topic of dyslexia, used the features of Facebook and other various digital tools to compose original "'mashed' texts (p. 9), images, and videos. It is important to note, however, that it was Facebook that played the "catalytic role'" (p. 16) for learning in the space. These three case studies take place in unique or exceptional classroom settings (an alternative to incarceration program, a digital media studies class, and a Facebook group, respectively). As a result, such research is still needed in more mainstream classroom settings.

\section{Conclusion}

Through a re-examination and re-grouping of Leander and McKim's work, it is evidence that as technologies change, the goal of social outreach remains. To put it another way, this work continuously enforces the idea that even in our connected and digitally mediated world, the desire to seek and foster connections among people remains. Lewis and Fabos (2005) concluded: "the maintenance of social relationships has been found to be a central function of online communication networks in general" (p. 475). For the students using Whyville, Webkinz, or IM in school, they all used them for continued social interaction. Affinity spaces online paralleled affinity spaces offline. Now, they are even more accessible, no longer hindered by limitations of physical space.

The fear of the unknown future, often following an influx of new technological changes (i.e., the automobile, the radio, the television, the cell phone), may lead to increased worry about technologically induced social isolation, where a child is 'plugged-in' to a device and not participating in the 'real world.' De Almeida et al. (2015) offered a rebuttal: "to be online is almost always to participate and to activate a close network of peers" (p. 1445). Others argue less out of fear of the unknown but fear of internet addiction. Johnson and Keane (2015) suggest otherwise, arguing that, despite their participants "ongoing consumption and production" (p. 15) online, users of the Internet do not perceive this as 
"time robbery" (p. 15) where time spent online is wasted or stolen. Rather, "these users appear to be using the Internet instead of being used by it" (p. 15, emphasis added).

Despite these potential fears, the ethnographic research of the on/offline realm suggest that people desire to connect to others. Kofoed and Larsen (2016) describe this as the "intimacy" (p. 12) built by social worlds. When young people share an ugly selfie or a doodle over a picture, young people are experiencing intimacy and closeness. As Leander and McKim sought to blur the lines to an indistinguishable degree between online and offline worlds, the research continues to show that despite this blurred line, one human connecting, reaching out into the 'world' remains the unending desire. 


\section{References}

Aarsand, P. A. (2008). Frame switches and identity performances: Alternating between online and offline. Text \& Talk, 28(2), 147-165.

Arora, P. (2011). Online social sites as virtual parks: An investigation into leisure online and offline. The Information Society, 27(2), 113-120.

Barden, O. (2013). New approaches for new media: Moving towards a connected methodology. Qualitative Research Journal, 13(1), 6-24.

Bulfin, S., \& North, S. (2007). Negotiating digital literacy practices across school and home: Case studies of young people in Australia. Language and Education, 21(3), 247-263.

Burnett, C. (2014). Investigating pupils' interactions around digital texts: A spatial perspective on the "classroom-ness" of digital literacy practices in schools. Educational Review, 66(2), 192-209.

Davies, J. (2012). Facework on Facebook as a new literacy practice. Computers \& Education, 59(1), 19-29.

Davies, J. (2013). Trainee hairdressers' uses of Facebook as a community of gendered literacy practice. Pedagogy, Culture \& Society, 21(1), 147-169.

de Almeida, A. N., Delicado, A., de Almeida Alves, N., \& Carvalho, T. (2015). Internet, children and space: Revisiting generational attributes and boundaries. new media \& society, 17(9), 1436-1453.

Dirksen, V., Huizing, A., \& Smit, B. (2010). 'Piling on layers of understanding': The use of connective ethnography for the study of (online) work practices. new media \& society, 12(7), 1045-1063.

Dochartaigh, N. O. (2007). Conflict, territory and new technologies: Online interaction at a Belfast interface. Political Geography, 26(4), 474-491.

Dowdall, C. (2006). Dissonance between the digitally created words of school and home. Literacy, 40(3), 153-163.

Feldon, D. F., \& Kafai, Y. B. (2008). Mixed methods for mixed reality: Understanding users' avatar activities in virtual worlds. Educational Technology Research and Development, 56(5-6), 575-593.

Fields, D. A., \& Kafai, Y. B. (2009). A connective ethnography of peer knowledge sharing and diffusion in a tween virtual world. International Journal of ComputerSupported Collaborative Learning, 4(1), 47-68. 
Fields, D. A., \& Kafai, Y. B. (2010). Knowing and throwing mudballs, hearts, pies, and flowers: A connective ethnography of gaming practices. Games and Culture, 5(1), 88-115.

Humphreys, L., Von Pape, T., \& Karnowski, V. (2013). Evolving mobile media: Uses and conceptualizations of the mobile internet. Journal of Computer-Mediated Communication, 18(4), 491-507.

Johnson, N. F., \& Keane, H. (2015). Internet addiction? Temporality and life online in the networked society. Time \& Society, $0961463 X 15577279$.

Jonsson, C., \& Muhonen, A. (2014). Multilingual repertoires and the relocalization of manga in digital media. Discourse, Context \& Media, 4, 87-100.

Kafai, Y. B., Feldon, D., Fields, D., Giang, M., \& Quintero, M. (2007). Life in the times of Whypox: A virtual epidemic as a community event. In C. Steinfield, B. Pentland, M. Ackerman, \& N. Contractor (Eds.), Communities and Technologies 2007 (pp. 171-190). New York: Springer.

Kofoed, J., \& Larsen, M. C. (2016). A snap of intimacy: Photo-sharing practices among young people on social media. First Monday, 21(11).

Lam, W. S. (2006). Re-envisioning language, literacy, and the immigrant subject in new mediascapes. Pedagogies: An International Journal, 1(3), 171-195.

Lammers, J. C. (2013). Fangirls as teachers: Examining pedagogic discourse in an online fan site. Learning, Media and Technology, 38(4), 368-386.

Leander, K. M., \& Lovvorn, J. F. (2006). Literacy networks: Following the circulation of texts, bodies, and objects in the schooling and online gaming of one youth. Cognition and Instruction, 24(3), 291-340.

Leander, K. M., \& McKim, K. K. (2003). Tracing the everyday 'sitings' of adolescents on the internet: A strategic adaptation of ethnography across online and offline spaces. Education, Communication \& Information, 3(2), 211-240.

Leander, K. M., \& Mills, S. (2007). Chapter Nine: Transnational development of an online role player game by youth. Counterpoints, 310, 177-195.

Lewis, C., \& Fabos, B. (2005). Instant messaging, literacies, and social identities. Reading Research Quarterly, 40(4), 470-501.

Lund, A. (2006). The multiple contexts of online language teaching. Language Teaching Research, 10(2), 181-204. 
Madge, C., Meek, J., Wellens, J., \& Hooley, T. (2009). Facebook, social integration and informal learning at university: 'It is more for socialising and talking to friends about work than for actually doing work'. Learning, Media and Technology, 34(2), 141-155.

Mallan, K., Foth, M., Greenaway, R., \& Young, G. T. (2010). Serious playground: using Second Life to engage high school students in urban planning. Learning, Media and Technology, 35(2), 203-225.

Mallan, K. M., Singh, P., \& Giardina, N. (2010). The challenges of participatory research with 'tech-savvy'youth. Journal of Youth Studies, 13(2), 255-272.

McGinnis, T., Goodstein-Stolzenberg, A., \& Saliani, E. C. (2008). "indnpride": Online spaces of transnational youth as sites of creative and sophisticated literacy and identity work. Linguistics and Education, 18(3), 283-304.

Merchant, G. (2007). Mind the gap (s): Discourses and discontinuity in digital literacies. E-Learning and Digital Media, 4(3), 241-255.

Pérez-Fragoso, C. (2011). Between physical and virtual spaces: The literacy practices of high school students. Counterpoints, 387, 129-151.

Prinsen, F., de Haan, M., \& Leander, K. M. (2015). Networked identity: how immigrant youth employ online identity resources. Young, 23(1), 19-38.

Schmier, S. (2014). Popular culture in a digital media studies classroom. Literacy, 48(1), 39-46.

Searle, K. A., \& Kafai, Y. B. (2012). Beyond freedom of movement: Boys play in a tween virtual world. Games and Culture, 7(4), 281-304.

Stæhr, A. (2015). Reflexivity in Facebook interaction-Enregisterment across written and spoken language practices. Discourse, Context \& Media, 8, 30-45.

Stewart, A. S. (2011). Text and response in the relationship between online and offline religion. Information, communication \& society, 14(8), 1204-1218.

Stirling, E. (2014). "We use Facebook to chat in lectures, of course!" Exploring the use of a Facebook group by first-year undergraduate students for social and academic support. In M. Kent \& T. Leaver (Eds.), An Education in Facebook? Higher Education and the World's Largest Social Network (pp. 23-31). New York: Routledge.

Stirling, E. (2016). Technology, time and transition in higher education-two different realities of everyday Facebook use in the first year of university in the UK. Learning, Media and Technology, 41(1), 100-118. 
Vasudevan, L. (2010). Education remix: New media, literacies, and the emerging digital geographies. Digital Culture \& Education, 2(1), 62-82.

Walker, D. M. (2010). The location of digital ethnography. Cosmopolitan Civil Societies: an interdisciplinary journal, 2(3), 23-39.

Wargo, J. M. (2015). Spatial stories with nomadic narrators: Affect, Snapchat, and feeling embodiment in youth mobile composing. Journal of Language and Literacy Education, 11(1), 47-64.

Warner, J. (2016). Adolescents' dialogic composing With mobile phones. Journal of Literacy Research, 48(2), 164-191.

Williams, M. (2007). Avatar watching: Participant observation in graphical online environments. Qualitative Research, 7(1), 5-24.

Wohlwend, K. E. (2009). Early adopters: Playing new literacies and pretending new technologies in print-centric classrooms. Journal of Early Childhood Literacy, 9(2), 117-140.

Wohlwend, K. E., Vander Zanden, S., Husbye, N. E., \& Kuby, C. R. (2011). Navigating discourses in place in the world of Webkinz. Journal of Early Childhood Literacy, 11(2), 141-163. 